\title{
Rare complications associated with epidural blood patches
}

\author{
Étienne de Médicis, MD
}

Received: 21 October 2009/Accepted: 9 November 2009/Published online: 5 January 2010

(c) Canadian Anesthesiologists' Society 2009

\section{To the Editor,}

I read with great interest the recently published case report of Drs. Mehta and Tarshis describing their experience with repeated large-volume epidural blood patch for the treatment of spontaneous intracranial hypotension. ${ }^{1}$ While the authors observed a successful outcome using this approach and identified potential complications of epidural blood patch, they failed to mention a little-known complication of high volume epidural injection, i.e., visual loss. $^{2}$ Visual loss associated with epidurals is rarely reported in the literature; a recent review in 2005 found 12 cases. ${ }^{3}$ In these cases, the volume of injectate varied from 20 to $120 \mathrm{~mL}$ with resulting retinal hemorrhage. Seventynine percent of the patients fully recovered. The pathophysiology is thought to be secondary to the sudden increase of epidural pressure during epidural injection, which is transmitted up to the optic nerve sheath rupturing the retinal blood vessels. These reports highlight the importance of slowly injecting fluids into the epidural space. At this point, it is unknown whether intracranial hypotension is protective against this potentially devastating complication.

Competing interests None declared.

\section{References}

1. Mehta B, Tarshis J. Repeated large-volume epidural blood patches for the treatment of spontaneous intracranial hypotension. Can J Anesth 2009; 56: 609-13.

É. de Médicis, MD ( $\square)$

CHU Sherbrooke, Sherbrooke, Canada

e-mail: estria1@globetrotter.net
2. Purdy EP, Ajimal GS. Vision loss after lumbar epidural steroid injection. Anesth Analg 1998; 86: 119-22.

3. Gill JB, Heavner JE. Visual impairment following epidural fluid injections and epiduroscopy: a review. Pain Med 2005; 6: 367-74.

\section{Reply}

We thank Dr. de Médicis for his interest in our recently published study and also for reminding all of us of a rare but clinically significant complication of epidural injections. As stated in his letter, the putative mechanism of visual loss is a sudden increase in intracranial pressure transmitted from the epidural space causing compression of the optic nerve and its related vasculature. Exact risk factors are unknown, as this is a rare complication considering the number of epidural injections that are performed in routine clinical practice, especially for obstetric analgesia and anesthesia. Nonetheless, under the principle of primum non nocere, it is important to be aware of all potential complications of our practice.

Competing interests None declared.

Jordan Tarshis, MD

Sunnybrook Health Sciences Centre, Toronto, Canada 